\title{
ANALISIS PENGARUH PEMBEBANAN TERHADAP TORKA MOTOR INDUKSI TIGA PHASA PADA PLTU TENAYAN RAYA
}

\author{
Wahid Syawaluddin ${ }^{1}$, Atmam ${ }^{2}$, Zulfahri ${ }^{3}$ \\ Program Studi Teknik Elektro, Fakultas Teknik, Universitas Lancang Kuning \\ Jl. Yos Sudarso Km. 8 Rumbai, Pekanbaru, Telp. (0761) 52324 \\ Email : syawal.daya@gmail.com, atmam@unilak.ac.id, zulfahri@unilak.ac.id
}

\begin{abstract}
ABSTRAK
Motor induksi tiga phasa merupakan jenis motor yang paling sering digunakan di industri. Hal ini dikarenakan motor induksi memiliki beberapa kontruksi peralatan yang sederhana dan biaya perawatannya yang relatif rendah. Besarnya beban yang dapat di suplai oleh motor tergantung dengan besarnya torka mekanik yang dihasilkan. Pada tugas akhir ini dibahas tentang motor induksi tiga phasa sebagai mobile crusher. Penelitian ini dilakukan pada motor induksi tiga phasa sebagai mobile crusher untuk penghancur batubara menjadi bongkahan yang lebih kecil yang memerlukan torka yang besar saat beroperasi. Namun saat motor induksi beroperasi terjadi trip. Sehingga motor induksi tidak beroperasi, dimana arus yang terukur sebesar 95 Amper. Berdasarkan hasil penelitian diperoleh torka motor induksi pada arus motor induksi 18,8 Amper, daya input 156,3 kW, sebesar 1.990,22 N.m dan torka pada saat arus 95 Amper, daya input 789,8 kW, sebesar 10.056,97 N.m.
\end{abstract}

Kata kunci : Arus, daya, torka motor induksi.

\begin{abstract}
Three-phase induction motors are the most-widely used kind of motor in industry. The reasons are because they have simple tool-construction as well as relatively low-cost maintenance. The amount of electrical load supplied by a motor depends on how high the mechanical torque produced. The study was conducted on a three-phase induction motor in a mobile crusher, crushing coals into smaller chunks in which extremely high torque is required during operation. However, while operating in such condition, induction motor experienced trips. As a result, induction motor stopped operating, where measured current was 95 Amps. The results of the study show that the torque value of the induction motor with 18,8 Amps current, and 156,3 $\mathrm{kW}$ input power is 1.990,22 N.m, while with 95 Amps current and 789,8 kW input power is 10.056,97 N.m.
\end{abstract}

Keywords : Current, Power, Induction Motor Torque

\section{PENDAHULUAN}

Pada PLTU Tenayan Raya batubara merupakan hal yang sangat penting. Karena batubara merupakan salah satu sumber daya alam yang bisa dimanfaatkan untuk bahan bakar sebagai tenaga awal (prime mover). Dengan kata lain kualitas, jenis, dan ukuran menjadi hal yang perlu diperhatikan untuk kelancarannya proses produksi. Tetapi sebelum digunakan untuk bahan bakar batubara terlebih dahulu harus dihancurkan sehingga hasilnya berupa serbuk [1].
Sebelum melakukan penghancuran, harus terlebih dahulu memperhatikan besarnya ukuran batubara. Karena semakin bagus kualitas dan semakin besar ukuran dari batubara maka akan berpengaruh pada besarnya torka motor induksi yang ditimbulkan saat beroperasi. Besarnya ukuran batu bara yang diterapkan sebesar < $30 \mathrm{~mm}$ [2]. Jika ukuran batubara melebihi ketentuan akan mengakibatkan motor induksi pada mesin mobile crusher mengalami gangguan saat beroperasi. 


\section{METODE PENELITIAN}

\section{Prinsip kerja motor induksi}

Prinsip kerja motor induksi, yaitu [3] :

1. Apabila sumber tegangan tiga phasa di pasang pada kumparan stator, timbulah medan putar dengan kecepatan.

$n_{S}=\frac{120 f}{p}$

2. Medan putar stator tersebut akan memotong batang konduktor pada motor.

3. Akibatnya pada kumparan rotor timbul tegangan induksi (GGL) sebesar.

$$
E_{2 S}=4,44 f_{2} n_{2} \text { ( satu fasa) }
$$

dimana $E_{2 s}$ adalah tegagan induksi pada satu rotor berputar.

4. Karena kumparan rotor merupakan rangkaian yang tertutup, GGL (E) akan menghasilkan arus (I).

5. Adanya arus (I) di dalam medan magnet menimbulkan gaya $(\mathrm{F})$ pada motor.

6. Bila kopel mula yang di hasilkan oleh gaya (F) pada rotor cukup besar untuk memikul kopel beban, rotor akan berputar searah dengan medan putar stator.

7. Seperti telah di jelaskan pada (3) tegangan induksi tmbul karena terpotongnya batang konduktor (rotor) oleh medan putar stator. Artinya agar tegangan terinduksi di perlukan adanya perbedaan relative antara kecepatan medan putar stator $\left(n_{s}\right)$ dengan kecepatan berputar rotor $\left(n_{r}\right)$.

8. Perbedaan kecepatan antara $n_{s}$ dan $n_{r}$ disebut slip (s) dinyatakan dengan :

$$
s=\frac{\left(n_{s}-n_{r}\right)}{n_{s}} \times 100 \%
$$

9. Bila $n_{r}=n_{s}$, tegangan tidak akan terinduksi dan arus tidak mengali pada kumparan jangkar rotor, dengan demikian tidak di hasilkan kopel. Kopel motor akan di timbulkan apabila $n_{r}$ lebih kecil dari $n_{s}$.

10. Dilihat dari cara kerjanya, motor induksi di sebut juga sebagai motor tak serempak

\section{Konsep Dasar Motor Induksi}

Tegangan tiga phasa diberikan pada belitan stator dan arus stator tiga phasa mengalir. Arus ini menghasilkan medan magnet $\mathrm{B}_{s}$ yang berputar secara berlawanan arah jarum jam. Kecepatan putar sinkron medan magnet dirumuskan [4] :

$$
n_{s y n c}=\frac{120 \times f_{s e}}{p}
$$

Putaran medan magnet $\mathrm{B}_{s}$ ini melewati batang rotor dan menginduksi tegangan di dalamnya. Tegangan induksi pada rotor dapat dihitung dengan persamaan adalah [4] :

$$
e_{\text {ind }}=(v \times B) \times l
$$

\section{Daya Motor Induksi Tiga Phasa}

Untuk menghitung daya motor induksi, adalah [3] :

$$
\left(P_{1}\right)_{3 p h}=3 \times V_{t} \times I_{s} \times \cos \varphi
$$

Atau :

$$
\left(P_{1}\right)_{1 p h}=\sqrt{3} \times V_{t} \times I_{s} \times \cos \varphi
$$

Slip

Tegangan yang diinduksi pada rotor motor induksi bergantung pada kecepatan rotor relatif terhadap medan magnet. Karena karakteristik motor induksi tergantung pada tegangan dan arus rotor, seringkali lebih logis untuk dibicarakan kecepatan relatif ini. Dua istilah biasanya digunakan untuk mendefinisikan putaran relatif rotor terhadap medan magnet. Salah satunya adalah kecepatan slip, yang didefinisikan sebagai perbedaan antara kecepatan sinkron dan kecepatan rotor, ditulis dengan persamaan [4] :

$$
n_{\text {slip }}=n_{\text {sync }}-n_{m}
$$

\section{Frekuensi}

Berubah-ubahnya kecepatan putar rotor akan mengakibatkan berubah ubahnya nilai slip dari saat start $(100 \%)$ sampai saat berputar pada kecepatan normal/stasioner ( $0 \%)$, yaitu $n_{s}=n_{r}$. Rotor dalam keadaan stasioner, Frekuensi arus rotor sama dengan frekuensi arus sumber. Jika rotor mulai bergerak (start), frekuensi arus rotor tergantung pada slip atau kecepatan $\left(n_{s}-n_{r}\right)$. frekuensi medan putar stator adalah $f_{s}$ dimana [5] : 


$$
f_{s}=\frac{n_{s} p}{120}
$$

sedangkan frekuensi di bangkitkan pada belitan rotor adalah $f_{r}$, dimana [5] :

$$
f_{r}=\frac{\left(n_{s}-n_{r}\right) p}{120}
$$

\section{Rangkaian Ekivalen Motor Induksi.}

Kerja motor induksi juga seperti kerja transformator adalah berdasarkan prinsip induksi elektromagnet. Oleh karena itu, motor induksi dapat dianggap sebagai transformator dengan rangkaian sekunder yang berputar. Hingga motor induksi dapat digambarkan seperti Gambar 1 [3]. Oleh karena itu, motor induksi dapat dianggap sebagai trafo dengan kumparan sekundar yang berputar.

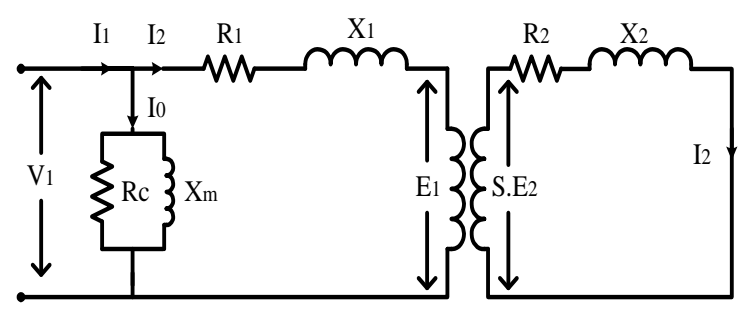

Gambar 1 Rangkaian Motor Induksi.

Perubahan frekuensi sumber pada motor induksi 3 phasa akan mempengaruhi besarnya impedansi kumparan motor, karena kumparan motor induksi mengandung reaktansi induktif. Gambar 2 menunjukan rangkaian ekivalen motor induksi [5].

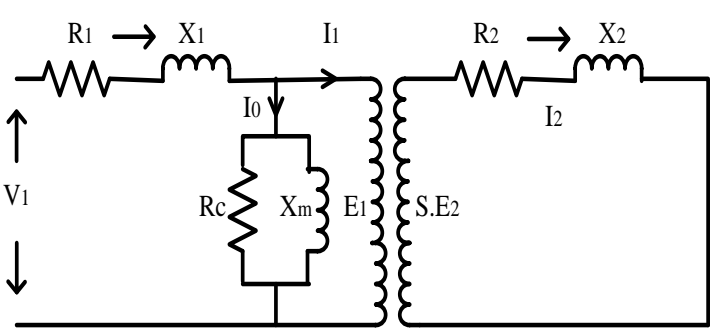

Gambar 2 Rangkaian ekivalen motor induksi.

\section{Torsi Motor Induksi.}

Dari rangkaian ekivalen yang ditunjukkan Gambar 2 maka dapat dicari nilai arus $I_{2}^{\prime}$ adalah [3]:

$$
I_{2}^{\prime}=\frac{E_{1}}{\sqrt{\left(a^{2} R_{2} / S\right)^{2}+\left(a^{2} X_{2}\right)^{2}}}
$$

Dan :

$$
\cos \varphi=\frac{\text { tahanan }}{\text { impedansi }}=\frac{a^{2} R_{2} / s}{\sqrt{\left(a^{2} R_{2} / s\right)^{2}+\left(a^{2} X_{2}\right)^{2}}}
$$

$$
P=T \omega=3 E_{1} I_{2}^{\prime} \cos \varphi
$$

Maka :

$$
T=\frac{P}{\omega}=\frac{3}{\omega} E_{1} I_{2}^{\prime} \cos \varphi
$$

Adapun besarnya torsi atau kopel rotor motor induksi tiga phasa adalah sebagai berikut [5]:

$$
\frac{(R P D)}{746}=\frac{2 \pi N_{r}}{33000} \times\left(T_{r s}\right)_{3 p h}
$$

Atau :

$$
\begin{aligned}
(R P D)_{3 p h} & =2 \pi N_{r} \times\left(T_{r s}\right)_{3 p h} \times 0,02 \\
& =\frac{\omega_{r} \times\left(T_{r s}\right)_{3 p h}}{60}
\end{aligned}
$$

Jadi :

$$
\left(T_{r s}\right)_{3 p h}=9,55 \frac{\left(P_{m}\right)_{r 3 p h}}{N_{r}}
$$

Atau :

$$
\left(T_{r s}\right)_{3 p h}=9,55 \frac{\left(P_{i n}\right)_{r 3 p h}}{N_{s}}
$$

Adapun torsi poros $\left(\mathrm{T}_{\mathrm{sh}}\right) 3$ phasa adalah [5]:

$$
\begin{aligned}
\left(T_{s h}\right)_{3 p h} & =\frac{\left(P_{o}\right)_{r 3 p h}}{\frac{2 \pi N_{r}}{60}} \\
& =9,55 \frac{\left(P_{o}\right)_{r 3 p h}}{N_{r}}
\end{aligned}
$$




\section{HASIL DAN PEMBAHASAN}

\section{Analisa Perhitungan Daya Motor Induksi Tiga Phasa Terhadap Perubahan Arus}

Berdasarkan data yang diperoleh dari lapangan maka dapat di peroleh data untuk dianalisa. Untuk menghitung analisa daya input yang terdapat pada motor induksi tiga phasa pada mobile crusher di PLTU Tenayan Raya.

\section{Pada data nameplate motor induksi tiga phasa}

Pada data nameplate motor induksi tiga phasa nilai arus yang tercantum sebesar 40,5 Amper, dengan tegangan 6000 Volt, dan faktor daya 0,8 , maka :

$$
\begin{aligned}
\left(P_{1}\right)_{3 p h} & =\sqrt{3} \times V_{t} \times I_{s} \times \cos \varphi \\
& =\sqrt{3} \times 6000 \times 40,5 \times 0,8 \\
& =336.710,68 \mathrm{Watt} \\
& =336,71 \mathrm{~kW}
\end{aligned}
$$

Berdasarkan dari analisa perhitungan daya motor induksi tiga phasa terhadap perubahan arus maka dapat disimpulkan bahwa nilai dari arus terhadap daya motor induksi berbanding lurus. Hasil dari Perhitungan ditunjukkan pada tabel 1 :

Tabel 1 Hasil Analisa Daya Berbanding Lurus Terhadap Arus Pada Motor Induksi Tiga Phasa.

\begin{tabular}{cccccc}
\hline No & Tanggal & $\begin{array}{c}\text { Tegangan } \\
\text { (Volt) }\end{array}$ & $\begin{array}{c}\text { Arus } \\
\text { (Amper) }\end{array}$ & $\begin{array}{c}\text { Faktor } \\
\text { Daya }\end{array}$ & $\begin{array}{c}\text { Daya } \\
\text { (Watt) }\end{array}$ \\
\hline 1 & $21-S e p-2017$ & 6000 & 19,9 & 0,8 & $165.445,49$ \\
2 & $22-S e p-2017$ & 6000 & 20,2 & 0,8 & $167.939,65$ \\
3 & $23-S e p-2017$ & 6000 & 18,8 & 0,8 & $156.300,26$ \\
4 & $24-S e p-2017$ & 6000 & 95 & 0,8 & $789.815,17$ \\
\hline
\end{tabular}

Hasil perhitungan dari Tabel 1 dapat digambarkan dengan grafik Gambar 3 yang menunjukkan nilai perubahan arus terhadap nilai daya. Hasil dari perhitungan daya input motor induksi tiga phasa adalah pada arus 19,9 Amper diperoleh daya input sebesar 165.445,49 Watt atau 165,4 kW, pada arus 20,2 Amper diperoleh daya input sebesar 167.939,65 Watt atau 167,9 $\mathrm{kW}$, pada arus 18,8 Amper diperoleh daya input sebesar 156.300,26 Watt atau 156,3 kW, dan pada arus 95 Amper diperoleh daya input sebesar 789.815,17 Watt atau 789,8 kW.

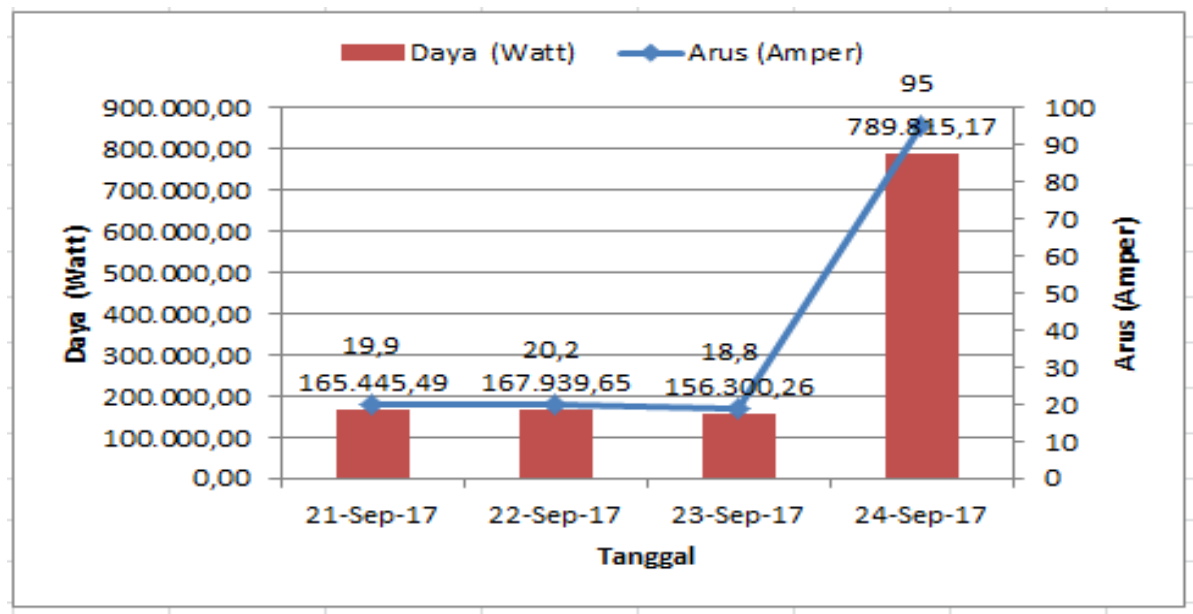

Gambar 3 Grafik Arus Terhadap Daya Motor Induksi Tiga Phasa.

\begin{abstract}
Analisa Perhitungan Torka Motor Induksi Tiga Phasa Terhadap Perubahan Daya

Berdasarkan data pada namplate motor induksi tiga phasa jumlah kutub 8 buah, dengan frekuensi sebesar $50 \mathrm{~Hz}$ dari sumber, maka
\end{abstract}

kecepatan medan putar kumparan stator pada dari motor induksi 3 adalah : 


$$
\begin{aligned}
n_{S} & =\frac{120 f}{p} \\
& =\frac{120 \times 50}{8} \\
& =750 \mathrm{rpm}
\end{aligned}
$$

Sehingga dengan menggunakan data pada namplate besarnya kecepatan medan putar pada rotor sebesar $741 \mathrm{rpm}$ maka besarnya kecepatan slip pada motor induksi adalah :

$$
\begin{aligned}
s & =\frac{n_{s}-n_{r}}{n_{s}} \times 100 \% \\
& =\frac{750-741}{750} \times 100 \% \\
& =1,2 \%
\end{aligned}
$$

Dengan mengetahui nilai $n_{s}=750 \mathrm{rpm}$, perubahan daya motor induksi dapat menganalisa besarnya torka yang akan ditimbulkan oleh motor induksi tiga phasa. Untuk menghitung analisa torka yang terdapat pada motor induksi tiga phasa pada mobile crusher di PLTU Tenayan Raya.

Pada data nameplate motor induksi tiga phasa

Pada data nameplate, nilai daya motor induksi tiga phasa sebesar 336.710,68 Watt, dan $n_{s}=750 \mathrm{rpm}$, maka :

$$
\begin{aligned}
\left(T_{r s}\right)_{3 p h} & =9,55 \times \frac{\left(P_{i n}\right)_{r 3 p h}}{N_{s}} \\
& =9,55 \times \frac{336.710,68}{750} \\
& =4.287,44 \text { N.m }
\end{aligned}
$$

Berdasarkan dari analisa perhitungan daya motor induksi tiga phasa terhadap perubahan torka maka dapat disimpulkan bahwa nilai dari daya terhadap torka motor induksi berbanding lurus. Dengan nilai $n_{s}=750$ dan Slip 1,2 \%, sehingga hasil dari perhitungan dapat ditunjukkan pada table 2 :

Tabel 2 Hasil analisa daya berbanding lurus terhadap torka.

\begin{tabular}{|c|c|c|c|}
\hline No & Tanggal & $\begin{array}{c}\text { Daya } \\
\text { (Watt) }\end{array}$ & $\begin{array}{c}\text { Torka } \\
(\mathrm{Nm})\end{array}$ \\
\hline 1 & 21 -Sep-2017 & $165.445,49$ & $2.106,67$ \\
\hline 2 & $22-$ Sep-2017 & $167.939,65$ & $2.138,43$ \\
\hline 3 & $23-$ Sep-2017 & $156.300,26$ & $1.990,22$ \\
\hline 4 & $24-$ Sep-2017 & $789.815,17$ & $10.056,97$ \\
\hline
\end{tabular}

Hasil perhitungan dari Tabel 2 dapat digambarkan dengan grafik Gambar 4 yang menunjukkan nilai perubahan daya terhadap nilai torka motor induksi tiga phasa pada mesin mobile crusher. Hasil perhitungan torka motor induksi tiga phasa adalah pada daya $165.445,49$ Watt atau $165,4 \mathrm{~kW}$ diperoleh torka sebesar 2.106,67 N.m, pada daya 167.939,65 Watt atau 167,9 $\mathrm{kW}$ diperoleh torka sebesar 2.138,43 N.m, pada daya 156.300,26 Watt atau $156,3 \mathrm{~kW}$ diperoleh torka sebesar 1.990,22 N.m, dan pada daya 789.815,17 Watt atau $789,8 \mathrm{~kW}$ diperoleh torka sebesar 10.056,97 N.m. 


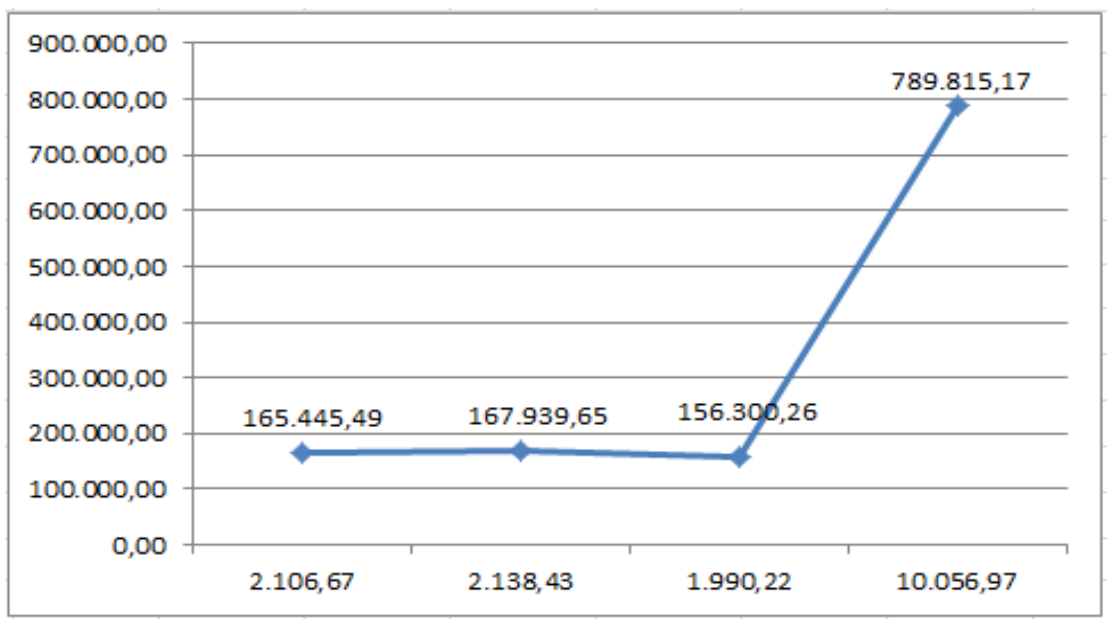

Gambar 4 Grafik daya terhadap torka.

Analisa Perhitungan Volume Besarnya Batubara

Besarnya volume ukuran batubara mempunyai hubungan dengan jumlah torka yang dihasikan. Karena torka yang dihasilkan nilainya semakin besar maka nilai arus juga akan naik. Untuk batas ukuran batu bara yang diizinkan berdasarkan handbook operator coal handling, maka ukuran batu bara adalah <30 $\mathrm{mm}$. Karena bentuknya yang tak seragam sebagai contoh untuk menghitung batubara yang bulat menyerupai bola [6]

$$
\begin{aligned}
V_{\text {(volume) }} & =\frac{4}{3} \pi r^{3} \\
& =\frac{4}{3} \pi 1.5^{3} \\
& =14,13 \mathrm{~cm}^{3}
\end{aligned}
$$

\section{Analisa Perhitungan Efisiensi Daya Motor Induksi Tiga Phasa}

Analisa perhitungan efisiensi motor induksi tiga phasa adalah :

$$
\begin{aligned}
\eta & =\frac{P_{\text {out }}}{P_{\text {in }}} \times 100 \% \\
& =\frac{315.000}{336.710} \times 100 \% \\
& =93,55 \%
\end{aligned}
$$

\section{Simulasi Motor Induksi Tiga Phasa}

Simulasi digunakan untuk mengukur kinerja dari suatu desain atau model sistem yang telah dirancang untuk mendapatkan hasil yang diinginkan. Hasil dari perhitungan, dapat di simulasikan pada program matlab. Adapun rangkain gambar untuk simulasi motor induksi tiga phasa dapat ditunjukkan pada Gambar 5 :

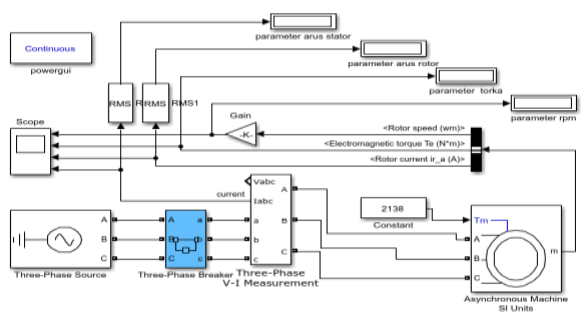

Gambar 5 Rangkaian Dengan Simulink Matlab

Pada simulink matlab ini juga dapat diketahui gelombang yang muncul, ketika aplikasi Simulink dijalankan/run. Berikut ini adalah hasil dari simulink matlab yang diberikan nilai torka sebesar 2.138 N.m. Seperti pada Gambar 6 yang merupakan gelombang pada motor induksi yang ditampilkan dari scope.

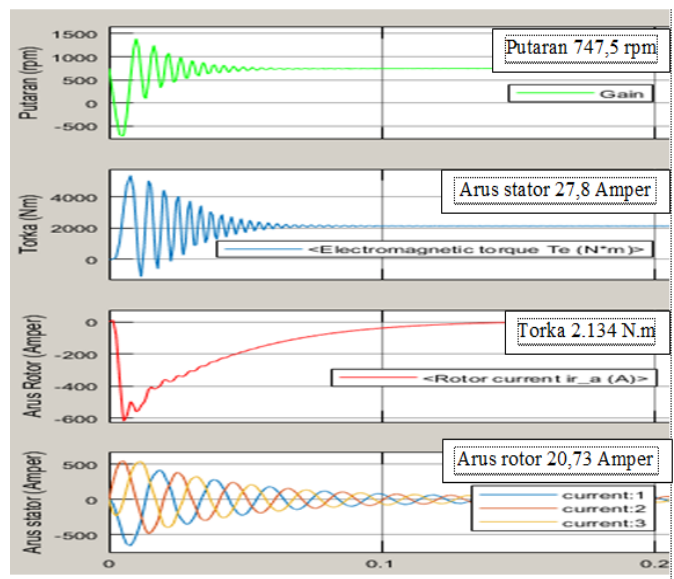

Gambar 6 Bentuk Gelombang Pada Simulink Matlab

Pada Gambar 7 menunjukkan gelombang putaran motor induksi tiga phasa yang ditampilkan dari scope. Ketika diberi nilai torka 
sebesar 2.138 N.m, maka menampilkan nilai putaran normal sebesar 747,5 rpm pada waktu 0,07 detik. Dari gambar grafik menunjukkan nilai putaran minimum sebesar $-717,8 \mathrm{rpm}$ pada waktu 0,005 detik, dan nilai putaran maksimum sebesar $1.392 \mathrm{rpm}$ pada waktu 0,09 detik.

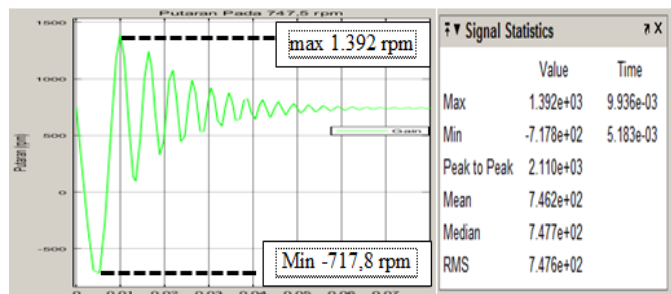

Gambar 7 Bentuk Gelombang Putaran Pada Simulink Matlab.

Pada Gambar 4.25 menunjukkan gelombang torka motor induksi tiga phasa yang ditampilkan dari scope. Ketika diberi nilai torka sebesar 2.138 N.m, maka akan menampilkan nilai torka normal sebesar 2.134 N.m pada waktu 0,07 detik. Dari gambar grafik menunjukkan nilai torka minimum sebesar 1.100 N.m pada waktu 0,012 detik, dan nilai torka maksimum sebesar 5.378 N.m pada waktu 0,007 detik

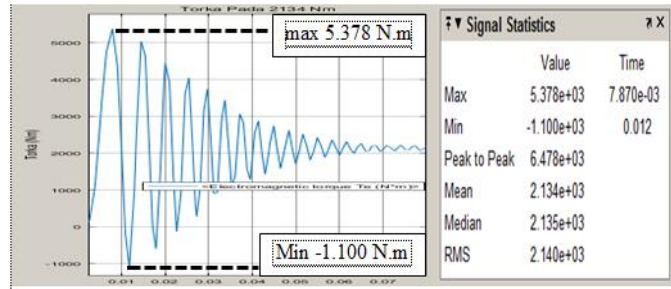

Gambar 8 Bentuk Gelombang Torka Pada Simulink Matlab.

Pada Gambar 9 menunjukkan gelombang arus rotor motor induksi tiga phasa yang ditampilkan dari scope. Ketika diberi nilai torka sebesar 2.138 N.m, maka akan menampilkan nilai arus rotor normal sebesar 20,7 Amper pada waktu 0,07 detik. Dari gambar grafik menunjukkan nilai arus rotor minimum sebesar - 618 Amper pada waktu 0,005 detik, dan nilai arus rotor maksimum sebesar 24,2 Amper pada waktu 1,348 detik.

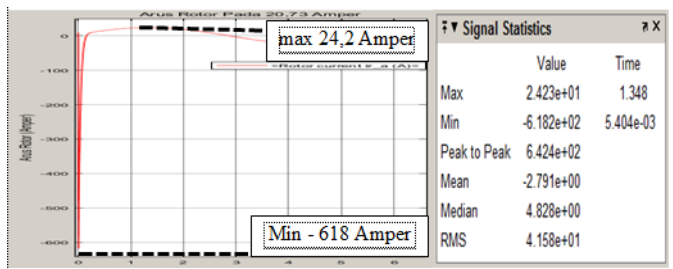

Gambar 9 Bentuk Gelombang Arus Rotor Pada Simulink Matlab.
Pada Gambar 10 menunjukkan gelombang arus stator motor induksi tiga phasa yang ditampilkan dari scope. Ketika diberi nilai torka sebesar 2.138 N.m, maka akan menampilkan nilai arus stator normal sebesar 27,8 Amper pada waktu 0,1 detik. Dari gambar grafik menunjukkan nilai arus stator minimum sebesar -487 Amper pada waktu 0,007 detik, dan nilai arus stator maksimum sebesar 548 Amper pada waktu 0,019 detik.

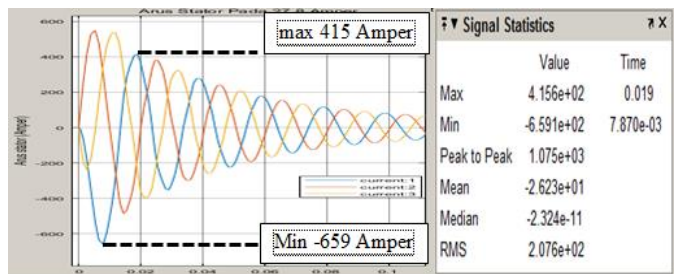

Gambar 10 Bentuk Gelombang Arus Stator Pada Simulink Matlab.

\section{KESIMPULAN}

Adapun kesimpulan yang dapat disampaikan adalah

1. Hasil dari perhitungan daya input motor induksi tiga phasa adalah pada arus 19,9 Amper diperoleh daya input sebesar 165,4 $\mathrm{kW}$, pada arus 20,2 Amper diperoleh daya input sebesar 167,9 kW, pada arus 18,8 Amper diperoleh daya input sebesar 156,3 $\mathrm{kW}$, pada arus 40,5 Amper diperoleh daya input sebesar $336,7 \mathrm{~kW}$, dan pada arus 95 Amper diperoleh daya input sebesar 789,8 $\mathrm{kW}$.

2. Hasil perhitungan torka motor induksi tiga phasa adalah pada daya $165,4 \mathrm{~kW}$ diperoleh torka sebesar 2.106,67 N.m, pada daya 167,9 $\mathrm{kW}$ diperoleh torka sebesar 2.138,43 N.m, pada daya $156,3 \mathrm{~kW}$ diperoleh torka sebesar 1.990,22 N.m, pada daya $336,7 \mathrm{~kW}$ diperoleh torka sebesar 4.287,44 N.m, pada daya $789,8 \mathrm{~kW}$ diperoleh torka sebesar $10.056,97$ N.m.

3. Motor induksi tiga phasa pada arus 40,5 Amper, memiliki daya input sebesar 336,71 $\mathrm{kW}$, kecepatan medan putar stator $750 \mathrm{rpm}$, dengan besar slip 1,2 \%, dan torka elektrik 4287,44 Nm serta torka mekanik sebesar 4059,71 N.m.

4. Dari hasil perhitungan besarnya volume batubara sebesar 14,13 $\mathrm{cm}^{3}$ dan masih sesuai menurut Handbook Operator Coal Handling. 


\section{DAFTAR PUSTAKA}

[1] Kusmindari, C., \& Pasmawati, Y., 2013, Redesain Mesin Penghancur Batubara Dengan Menggunakan Metode Zero, 10(12), 55-66. Jurnal Tekno. pp. 55-66., ISSN 1907-5243, Vol. 10, No. 2, Palembang.

[2] PT. PJB UBJOM, 2016, Handbook Operator Coal Handling, PT. PJB UBJOM PLTU Tenayan, Riau.

[3] Zuhal, 1991, Dasar Tenaga Listrik Dan Elektronika Daya, PT Gramedia, Jakarta.

[4] Chapman Stephen. J., 2012, Electric Machinery Fundamentals Fifth edition, Mc Graw Hill Higher Edication, New York.

[5] Rijono Yon, 1997, Dasar Teknik Tenaga Listrik Edisi Revisi, Andi, Yogyakarta.

[6] Syahbana, A., 2015, Alternatif Pemahaman Konsep Umum Volume Suatu Bangun Ruang, ISSN 2088-2157, Vol. 03, No. 02, Palembang. 